\title{
APROXIMACIÓN A LA ICONOGRAFÍA DE ROMA AETERNA COMO VÍA DE TRANSMISIÓN DE UN MITO
}

\author{
The iconography of Roma Aeterna as mean of transmission a myth
}

Javier ANDRÉS PÉREZ*

javierandresperę@usal.es

(Universidad de Salamanca)

Fecha de recepción: 25-01-2010

Fecha de aceptación: 05-02-2010

RESUMEN: La imagen verbal de Roma Aeterna es uno de los conceptos de mayor alcance en la Historia de Occidente. Su trayectoria discurre sin interrupción desde las postrimerías de la República Romana hasta finales del Bajo Imperio, manteniendo vivo su mensaje político en los siglos que siguieron a la desintegración del Imperio Romano.

El objetivo de esta comunicación es acercarnos al mito de Roma Aeterna a través de las representaciones que dieron forma a este concepto, partiendo de los elementos iconográficos de época imperial, y continuando con aquéllos que sobrevivieron a la Roma pagana manteniendo vigente su significado primigenio. De esta forma, nos aproximaremos a una valoración global del empleo de determinadas imágenes, aún presentes en el imaginario colectivo sobre Roma, desde una perspectiva transversal, con objeto de mostrar la absoluta necesidad de establecer lazos entre diferentes ramas de los estudios históricos como son la Historia y el Arte.

Palabras Clave: Roma Aeterna, Antigüedad Tardía, Iconografía, Rómulo, Fénix, Vesta

ABSTRACT: The verbal image of Roma Aeterna is one of the most long-lived concepts in Western History. Its tradition flows without interruption from the last decades of the Roman Republic to the end of the Empire. From that time onwards, the expression Roma Aeterna maintained its politic meaning. 
The aim of this paper is to approach the myth of Roma Aeterna through the representations that gave visual form to this concept, taking as starting point the iconographic elements from the Imperial period, to continue with those that overcome the Pagan Empire. Thus, we will value the global use of certain images from an inter-disciplinary point of view, specially those still present in the popular belief about Rome, in order to show the convenience of strengthening links between different fields, as History and History of Art.

Keywords: Roma Aeterna, Late Antiquity, Iconography, Romulus, Phoenix, Vesta.

"Entre lo religioso y lo social, lo doméstico y lo civico, no hay oposición ni corte neto, no más que entre lo sobrenatural y lo natural, entre lo divino y lo mundano"'.

\section{ACLARACIÓN METODOLÓGICA}

Como afirmó Vernant en su opúsculo sobre la religión griega, con frecuencia tendemos a pensar en límites, fronteras y espacios marcados por coordenadas geográficas y temporales: cubículos donde contener la información para que no se escape fuera de nuestro control. La realidad, sin embargo, fue distinta. Este autor, como tantos otros, puso de manifiesto la necesidad de abandonar los límites prefijados por décadas de inmovilismo metodológico, para dirigir la mirada hacia un universo de interconexiones entre el hombre y el medio en el que vivió.

El historiador, como explica Vernant, debe esforzarse, no sólo por ordenar la información válida y presentarla de forma comprensible, sino también por desentramar las claves del pensamiento humano, sin olvidar que el cosmos del hombre del pasado carecía de los límites y categorías de nuestra propia sociedad.

Partiendo de esta premisa nos encontraríamos con un segundo obstáculo, esta vez relativo al panorama de las investigaciones actuales. Hoy en día, la labor del historiador podría parecer bien definida, y sin embargo, una simple mirada al horizonte científico actual bastará para descorazonar a cualquier investigador que esté dando sus primeros pasos en el ámbito académico; al primer golpe de vista todo parece haber sido ya estudiado. En cierto modo, esta impresión es real. El siglo XX ha sido, sin lugar a dudas, el espacio de tiempo en el que más intensamente se ha analizado el pasado a lo largo de la historia. Los trabajos producidos en los últimos sesenta años destacan precisamente por su enorme cantidad y muchos de ellos por su probada calidad. Sin embargo, lo que podría parecer suficiente para negar las posibili- 
dades a un nuevo punto de vista, es lo que hoy en día abre las puertas de la investigación. Esto es así porque la sociedad en la que vivimos formula cuestiones muy distintas a las que se formularon años atrás, que fueron las que justificaron la necesidad de muchas investigaciones pretéritas. Por eso, una de las claves de la investigación de nuestra época es la interdisciplinariedad, esto es, construir una investigación original, con conclusiones novedosas, trabajando tangencialmente con retazos de los grandes temas y los grandes estudios anteriores. El punto de partida debe ser, como citaba anteriormente, la omisión de los límites que restringieron visiones anteriores.

Esta introducción viene justificada por la naturaleza de la investigación doctoral que me ocupa y de la que trataré, parcialmente, en este artículo. Uno de los aspectos metodológicos que condicionan mi trabajo es el principio de transversalidad, esto es, la necesidad de traspasar los límites de fuentes y disciplinas de muy distinto tipo, con objeto de establecer relaciones entre ellas. Esta premisa vino impuesta por el propio tema de mi trabajo, titulado "La idea de 'Eternidad de Roma' en la Antigüedad Tardía. Transformación urbana y percepción ideológica". Al tratarse de una investigación de concepto, el acercamiento a la información debe ser diacrónico y heterogéneo en cuanto a las fuentes, con objeto de aglutinar los datos, de por sí muy dispersos.

En este sentido, la iconografía puede servir como epítome para ejemplificar la necesidad de lanzar miradas transversales sobre la Historia, ya que, por un lado, durante siglos ha proporcionado una imagen física al mito de Roma, y por otro lado ilustra de forma práctica la necesidad de establecer lazos entre diferentes disciplinas. Además, para su correcta interpretación, la iconografía exige el dominio, tanto de las fuentes escritas como de los repertorios gráficos.

\section{ESTADO, RELIGIÓN Y CONQUISTA EN LA BASE DEL MTTO URBANO DE ROMA}

Es preciso hacer, en primer lugar, una breve semblanza de los diferentes aspectos que sirvieron para construir la idea de eternidad de Roma, y cómo estos fueron estableciéndose como base de un mito urbano de gran trascendencia y largo alcance en el tiempo; un concepto que ha perdurado a lo largo de siglos, superando situaciones históricas de muy diversa índole.

La idea de eternidad de Roma no sólo es obra de los propios romanos. Durante siglos, Europa se ha encargado de ir construyendo ese mito en torno a la Urbs, y por ello toda la cultura occidental participa de él. "Roma constituye uno de los lugares más míticos de la imaginación viajera de todas las épocas. Para quienes en el pasado sintieron algún tipo de inquietud artística -tuviera el alcance que tuviera-, Roma representó una especie de ideal. 
Sin embargo, como los ideales humanos son tan variados que difícilmente dos personas se refieren a lo mismo cuando hablan de aquello que desean o admiran, precisar el alcance de Roma como ideal es una cuestión muy compleja"2.

Para indagar en las bases de ese ideal y llegar a lo que hace de él algo universal, debemos recordar un aspecto decisivo del pensamiento romano: la creencia en la continua manifestación de lo sagrado en la vida cotidiana, y por tanto la consideración del mito de Roma, hoy absolutamente abstracto para nosotros, como un elemento aglutinante de la sociedad romana, real e incuestionable para quienes habitaron en un imperio capaz de dominar todo el Mediterráneo; pero también innegable para quienes heredaron su legado histórico e ideológico y lo preservaron durante la Edad Media y la Edad Moderna.

El mito de Roma se desgaja en un sinfín de facetas, de las cuales la Aeternitas Romae, es uno de sus pilares fundamentales. El concepto de eternidad, en términos generales, se refiere a la capacidad sobrenatural de algo o alguien para perpetuarse en el tiempo, exaltando doblemente sus orígenes remotos y su futuro imperecedero. Al combinar este concepto con la ciudad de Roma, obtenemos una idea que formó parte del conglomerado ideológico de la Roma Antigua. Para los ciudadanos del Imperio Romano, la eternidad fue un principio esencial del Estado y además una justificación patriótica para extender su cultura inmortal hasta donde fuera posible?

Kennard Rand afirmó que era posible vislumbrar las primeras referencias a la eternidad de Roma en la literatura latina del siglo II a. C. ${ }^{4}$, y de hecho, Cicerón es el primero que concibe la eternidad en términos de seguridad duradera, esto es, de Securitas Rei Publicae ${ }^{5}$. No obstante, la personificación de la Dea Roma, que luego pasará a ser llamada Roma Aeterna no recibe culto en la propia ciudad de Roma, como divinidad titular, hasta poco antes del cambio de era. Esto se debe a que la concepción de Roma como divinidad no se originó en terreno itálico, sino en las ciudades de Asia Menor conquistadas a lo largo de los siglos II y I a. C. por los ejércitos romanos. La tradición helenística de divinizar tanto a gobernantes como a personificaciones de ciudades dio como resultado los primeros templos y sacerdotes consagrados a la Dea Roma, en ciudades como Esmirna, Éfeso y Pérgamo, y desde allí su culto fue progresivamente trasladado hasta Italia, donde comenzó a ser aceptada bajo el Principado de Augusto ${ }^{6}$. De esta forma, a lo largo de todo el período imperial se produjo una fuerte asimilación entre la divinidad, el emperador y la ciudad, esto es, entre religión, poder y sede de ambas: tres elementos que compartían la misma sacralidad, y también el mismo sistema de representación. 
Pero además, una parte importante de la dimensión mítica de Roma se asentó también sobre los primeros estadios de la religión cívica romana, y en concreto en los cultos a ciertas divinidades asociadas a la Urbs, relacionadas doblemente con el mito fundacional y con la garantías de bienestar y seguridad, como es el caso de Salus' (Salus Publica Populi Romani) o Securitas (Securitas Rei Publicae). Estas dos deidades abstractas aseguraban la ventura del Estado y de sus ciudadanos 8 , y por ello su culto estuvo muy extendido entre toda la población; con frecuencia contaron con el patrocinio de las clases senatoriales durante el período republicano, y posteriormente gozaron de la protección imperial. Desde época temprana tuvieron sus propios templos, algunos de ellos de gran entidad, situados dentro de la ciudad de Roma, y más concretamente en la parte del Foro más próxima al Capitolio. En el caso de Salus, esta deidad era identificada con la salud y el bienestar, y su culto fue vinculado a la figura del emperador, quien se mostraba ante sus súbditos como la encarnación de las virtudes cívicas, entre las que también estaban Pietas, Victoria o Felicitas, de lo que derivaba su papel como garante de la seguridad del Estado. De la asociación de ambos cultos, tan frecuente en Roma, surgió el culto de Salus Augustorum ${ }^{10}$.

El interés de la institución imperial por promocionar determinadas deidades también se observa en el culto a Rómulo/Quirino, que se convirtió, en el siglo IV en una de las divinidades con más seguidores. Por un lado, Quirino fue identificado popularmente con Marte y Júpiter, los dioses más importantes del panteón romano, que también tenían su propio papel como protectores del Estado. Por otro lado, según el mito fundacional de Roma recogido por Tito Livio ${ }^{11}$, Rómulo era hijo de Marte y de la vestal Rhea Silvia; de nuevo, desde un punto de vista mítico, la vinculación entre Rómulo y el dios de la guerra establecía lazos entre la necesidad de alcanzar la victoria militar ${ }^{12}$ y las aspiraciones hacia conceptos cívicos elevados como la Aeternitas. Además, el mito fundacional de Roma nos muestra otro elemento que va a tener una larga vinculación con la idea de eternidad de la ciudad: el templo de Vesta, presente incluso antes de que Roma fuera fundada, donde las vírgenes vestales mantenían siempre vivo el fuego eterno de la ciudad.

En cualquier caso, si la figura de Rómulo se nos muestra como un símbolo evidente de la antigüedad y el pasado sagrado de la capital del Lacio, no podemos olvidar que también fue considerado un precursor de la figura del emperador. A partir de Augusto, su culto se asoció también a la figura del soberano, que fue proclamado en diversas ocasiones como el nuevo Rómulo, es decir, aquel que podía renovar simbólicamente la capital para asegurar su pervivencia ${ }^{13}$.

La Dea Roma Aeterna, mantuvo su culto hasta finales del siglo IV gracias al esfuerzo hecho por los últimos aristócratas paganos de la ciudad, incapaces de abandonar una tradición que ya contaba con más de tres siglos. 
Pero finalmente, el templo de Venus y Roma, elevado por el emperador Adriano y consagrado en el $135 \mathrm{~d}$. C. fue abandonado y el sacerdocio de los duocemviri Urbis Romae ${ }^{14}$, desapareció por la presión del cristianismo. Sin embargo, aunque los preceptos de la nueva religión oficial rechazaban cualquier culto o referencia a la Dea Roma, se mantuvo la idea de eternidad de la ciudad como una noción aparentemente desvinculada de sus originarias implicaciones religiosas paganas; como concepto, la Aeternitas Romae siguió siendo expresada en alusiones poéticas y patrióticas que demostraban un trasfondo teológico cada vez mayor ${ }^{15}$.

La consideración de la ciudad como un ente eterno va pareja a la condición sagrada del poder imperial, que perduró pese a los cambios religiosos y sociales, durante toda la Edad Media. La Historia ha demostrado que los elementos sagrados del poder son prácticamente inamovibles, lo que en un contexto como el de la Roma del siglo IV pudo servir para establecer lazos entre paganos y cristianos en un ambiente de enfrentamiento y transformación de las estructuras sociales, religiosas y económicas.

Sabemos, por del Códice Teodosiano ${ }^{16}$, que algunas tradiciones relacionadas con el concepto pagano de Urbs Aeterna, y por tanto con la configuración del mito urbano de Roma, fueron mantenidas por emperadores cristianos, como Valentiniano, Teodosio y Arcadio. Un ejemplo que ilustra la voluntad de hacer pervivir ese rasgo definitorio de la ciudad fue la celebración de la fiesta de los natales de Roma y Constantinopla hasta el año 389, y aún más, el hecho de que el Natalis Urbis ${ }^{17}$ romano se siguiera celebrando cada 21 de abril con carreras de caballos hasta el año $444^{18}$. Lo mismo sucedió con los Septimontia, una fiesta que se celebraba en honor de las siete colinas sagradas de Roma, que se mantuvo hasta mediados del siglo $\mathrm{V}^{19}$. Estas celebraciones están en relación con el deseo, no de anular ese capítulo del pasado pagano de la ciudad, sino de exaltar el sentimiento patriótico romano, más allá de los límites impuestos por los condicionantes religiosos del cristianismo. Si en un contexto de cambio permanente, como el que experimentó Italia en los siglos IV y V, el mensaje de la Aeternitas Romae se mantuvo, esto sólo puede deberse a su vigencia en tiempos de crisis, y a su utilidad como aglutinante social y condicionante patriótico para la ciudadanía romana, con independencia de las implicaciones paganas que hubiera podido tener en el pasado.

\section{Un BREVE RECORRIDO POR LA ICONOGRAFÍA DE ROMA AETERNA.}

En lo referente a la iconografía, ya hemos mencionado algunas divinidades, como Rómulo/Quirino, Salus o Vesta, que guardaron una estrecha relación con la dimensión mítica de Roma, y cuyas representaciones escul- 
tóricas y numismáticas sirvieron para dotar a la ciudad de una imagen reconocible. Pero el repertorio es mucho mayor, debido, fundamentalmente a una serie de factores, entre los que está, por ejemplo, la personalidad ecléctica de los romanos, capaces de asumir sistemas religiosos y representativos de otros pueblos ajenos a la tradición itálica. Además debemos tener en cuenta que el mito de Roma se fraguó durante un período muy prolongado de tiempo, en el que, tanto el concepto de eternidad como el de Imperio fueron modificándose progresivamente y adaptándose a las nuevas circunstancias.

La imagen de Roma lleva asociadas otras muchas imágenes vinculadas a los valores cívicos, urbanos y culturales de la civilización occidental. El propio concepto de imperio, tan retomado a lo largo de la historia europea, ha servido de ocasión para recuperar los valores imperecederos de Roma, incluyendo aquéllos que inciden directamente en la antigua capital.

En este apartado iremos desentramando algunos de esos elementos, partiendo de los más antiguos, y observando qué repercusiones han tenido a lo largo de la Historia. De este modo, debemos dirigir la mirada a la Magna Grecia, pues la primera imagen que poseemos de la Dea Roma, divinidad que dio forma personificada al mito urbano de la ciudad, procede de un didracma de la colonia griega de Locri Epizefiria (Calabria), datada en el 204 a. C. ${ }^{20}$ Esta representación de la Dea Roma entronizada sirvió como un modelo que fue posteriormente aceptado y utilizado por los propios romanos. Pero, aparte de este caso aislado en el contexto de la península itálica, la primera iconografía verdaderamente desarrollada sobre la personificación de la Urbs, debemos buscarla en Grecia, y más concretamente en lugares como Delfos, en la Grecia Continental y Esmirna, en Asia Menor; dos de las ciudades pioneras en la construcción de templos para el culto a Roma desde el 195 a. C., a las que más tarde se sumaron otras poleis del ámbito griego-helenístico, como la propia Atenas, desde aproximadamente el 170 a. C., o Éfeso y Pérgamo, hacia el 150 a. C. ${ }^{21}$

El modelo iconográfico de Roma elaborado en el contexto griego respondía a los patrones empleados en las divinidades titulares de las ciudades griegas, y éste, al mismo tiempo solía inspirarse en el de Atenea, si bien las divinidades menores eran representadas sentadas, mientras que Atenea era siempre mostrada en pie. Así pues, la imagen de Roma que llegó a Italia era la de una figura femenina entronizada, portando yelmo con cimera, lanza en la mano izquierda y una pequeña Niké en la derecha, así como un gran escudo ovalado a los pies del trono, o bien en un lateral del mismo (Figs. I-IV).

Así es como encontramos a Roma representada en soportes muy variados, desde el cuño de una moneda, hasta esculturas monumentales o pinturas al fresco. Cualquiera de los ejemplos citados sirvió para representar tanto a la ciudad de Roma, como los valores cívicos encarnados por el Im- 
perio, lo que explica su larga vida y su presencia en muy distintos períodos y lugares, en los que fue necesario recurrir a esos principios con objetivos políticos y propagandísticos.

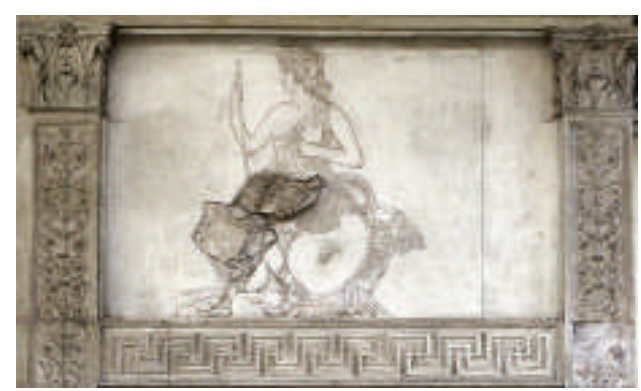

Fig. I. Dea Roma, en la imagen reintegrada de uno de los paneles del Ara Pacis de Augusto. Roma. 13-9 a. C.

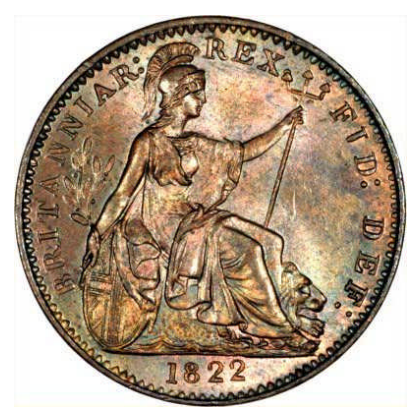

Fig. II. Cuarto de penique de Jorge III. Inglaterra, 1822.

La propia moneda romana se sirvió de la imagen de la Dea Roma con fines patrióticos, como podemos observar en un Antoniniano de Filipo II, acuñado en Antioquía (Fig. III), un ejemplo entre los muchos existentes, en el que podemos observar cómo el modelo fue difundido por todo el Imperio, y de qué modo las ciudades lo emplearon para demostrar su adhesión y sometimiento, no sólo a un sistema de gobierno, sino a una ciudad que era también una entidad sagrada.

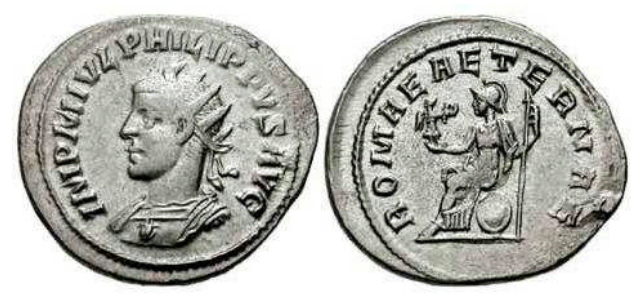

Fig. III. Antoniniano Filipo con la leyenda ROMAE AETERNAE en el reverso. Ceca de Antioquía de Siria.

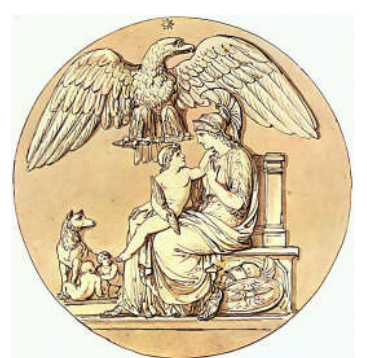

Fig. III. Antoniniano Filipo con la leyenda ROMAE AETERNAE en el reverso. Ceca de Antioquía de Siria.

Un caso paradigmático de recuperación de la iconografía de Roma en época contemporánea, es la creación del título de 'Re di Roma', esto es, de Rey de Roma por parte del Senado-Consulto de la ciudad en febrero de 1810 para Napoleón II. Una representación alegórica de Bartolomeo Pinelli pin- 
tada en 1811 (Fig. IV ${ }^{22}$ hace uso de la iconografía tradicional de la Dea Roma, junto con el águila imperial, la estrella que antaño representó al Sol Invictus, y la Loba Capitolina acompañada por Rómulo y Remo, todo un conglomerado iconográfico que sirve para resumir las elevadas aspiraciones de un título recién creado.

La Loba Capitolina está también presente en el ideario popular sobre la ciudad de Roma, y aún más que la propia representación de la Dea, la Loba se ha convertido en su símbolo más extendido. Su representación más célebre, aquélla escultura de bronce aún conservada en el Palacio de los Conservadores del Capitolio, y que supuestamente adornó el Senado de Roma, no era una obra romana ni etrusca, sino producto de una fundición medieval2 ${ }^{23}$. El mito fundacional de Roma la colocaba como Lupa Nutrix o Mater Nutritia de la ciudadanía, pues la Loba había alimentado a los fundadores de la ciudad, que eran la representación de toda su población. Una de las claves para entender su pervivencia fue, por un lado su originalidad iconográfica, y por otro, la enorme difusión que este modelo alcanzó en todo tipo de soportes durante el período imperial, desde monedas (Fig. V), estandartes militares, escultura exenta y multitud de relieves que decoraban espacios públicos en las capitales provinciales ${ }^{24}$.
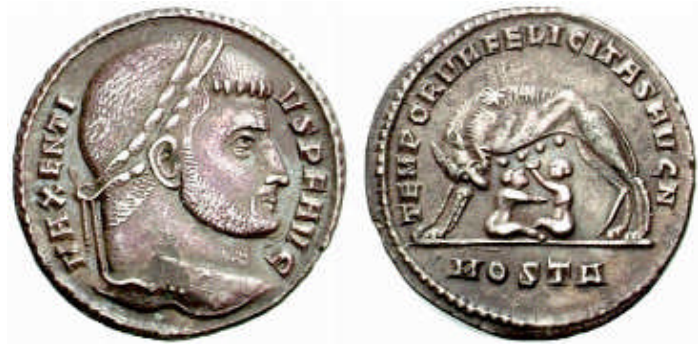

Fig. V. Moneda acuñada bajo el gobierno de Majencio en la ceca de Roma, en cuyo reverso aparece la Loba Capitolina amamantando a Rómulo y Remo. Este es el modelo que pudo tomar Antonio del Pollaiuolo para la realización de las dos figuras cinquecentistas de Rómulo y Remo, tal y como las conocemos hoy.

Tras la progresiva desintegración del Imperio Romano y la división de Italia en entidades políticas independientes, las aristocracias convertidas al cristianismo siguieron conservando el prestigio que habían cultivado durante siglos de paganismo. En Roma, las estructuras administrativas se mantuvieron, a pesar de los saqueos y del creciente dominio de la Iglesia, que llegó a controlar todos los resortes del poder. El Senado continuó siendo el organismo vertebrador de la vida política de Roma, y la Loba Capitolina, sorprendentemente, siguió manteniéndose como emblema de los orígenes de la ciudad. En cualquier caso, también tenemos documentos altomedievales que muestran una visión negativa de la Loba Capitolina, como símbolo de un paganismo vencido por el cristianismo. Un ejemplo claro sería el célebre 
díptico eborario de la Abadía de San Flaviano de Rambona, en Marcerata (Marche, Italia), fechado a mediados del siglo X (Fig. VI). En la placa izquierda del díptico se observa una escena de la Crucifixión de Cristo, acompañado por la Virgen y San Juan, con la peculiaridad iconográfica de llevar asociada una Loba Capitolina amamantando a Rómulo y Remo a los pies de la Cruz. Se trata de un caso discutido, cuya lectura más tradicional apunta hacia una imagen de victoria del cristianismo sobre el paganismo ${ }^{25}$. En la disposición de las escenas se aprecia una clara jerarquización de las figuras: a los pies, en la parte inferior, aparece la Loba Capitolina, con la cabeza vuelta en gesto agresivo, con objeto de proteger a su prole, pero en cualquier caso situada en un ámbito terrenal y claramente inferior. Sobre ella, la escena de la Crucifixión, coronada por la imago clipeata de Cristo en su ascenso a los cielos; una asociación de imágenes que podría remitir a la idea de redención para quienes practicaron el paganismo y se alimentaron espiritualmente de él. En definitiva, la lectura final de esta parte del díptico incidiría en una Salvación de carácter universal. Por otro lado, se produce una interesante asociación de carácter negativo con el relieve de la hoja de la derecha: la Loba Capitolina aparece espacialmente opuesta a la representación de la imagen de la María entronizada según el esquema de la Hodegetría bizantina. Se trata de dos maternidades de muy distinta naturaleza: la de la Loba, marcadamente antinatural, que podría incluso ser tachada de monstruosa, frente a la serena humanidad de la figura de la Virgen.

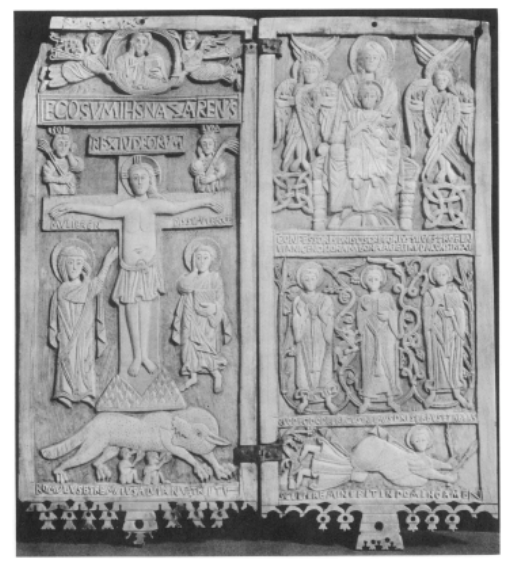

Fig. VI. Díptico de la Abadía de Rambona (Italia). Siglo X. Museo Cristiano (Vaticano). A los pies de la Loba aparece la inscripción: 'Romulus et Remulus a Lupa Nutriti'.

La inscripción de por si no tiene ninguna connotación negativa, pero puede establece una comparación iconográfica entre quienes se alimentaron de la cultura de Roma y quienes se alimentan simbólica y espiritualmente del Cuerpo de Cristo.

La Loba Capitolina, aunque no fue un tema especialmente recurrente en la iconografía medieval, se mantuvo en determinados contextos, sobre todo a partir del Trecento, cuando volverá a ser utilizada por Giovanni Pisano, y por Giovanni Lorenzo Turino a partir del Quattrocento. A partir del Renacimiento, cuando se recuperan las bases de la cultura clásica y las ciudades ita- 
lianas comienzan a recuperar su pasado romano desde un punto de vista material, con objeto de fortalecer los ánimos de sus ciudadanos. En Roma, el bronce de la Loba será restaurado, posiblemente, por Antonio del Pollaiuolo, y numerosas reproducciones se alzarán en la capital, como parte de la decoración de importantes edificios y fuentes, en forma de esculturas y elementos heráldicos, como en el Palaz:o Spada de Roma, que despliega en su fachada un impresionante conjunto de elementos clásicos.

Otro de los capítulos reseñables en la recuperación de la iconografía lupercal tuvo lugar en el siglo XX, bajo el gobierno de Benito Mussolini que, no sólo hizo limpiar el área forense de Roma con objeto de recobrar la imagen imperial de la $U r b s^{26}$, sino que además ordenó la reproducción en bronce de un gran número de copias, tanto de la Loba Capitolina como de la escultura de Augusto de Primaporta, que fueron ofrecidas como regalo diplomático a las ciudades extranjeras que mantenían algún lazo, bien histórico, o bien onomástico, con Roma -como son los casos de Mérida y Zaragoza-. Asimismo, durante el gobierno fascista, la Loba Capitolina fue un tipo iconográfico frecuentemente empleado en los monumentos dedicados a los caídos por Italia (Fig. VII).

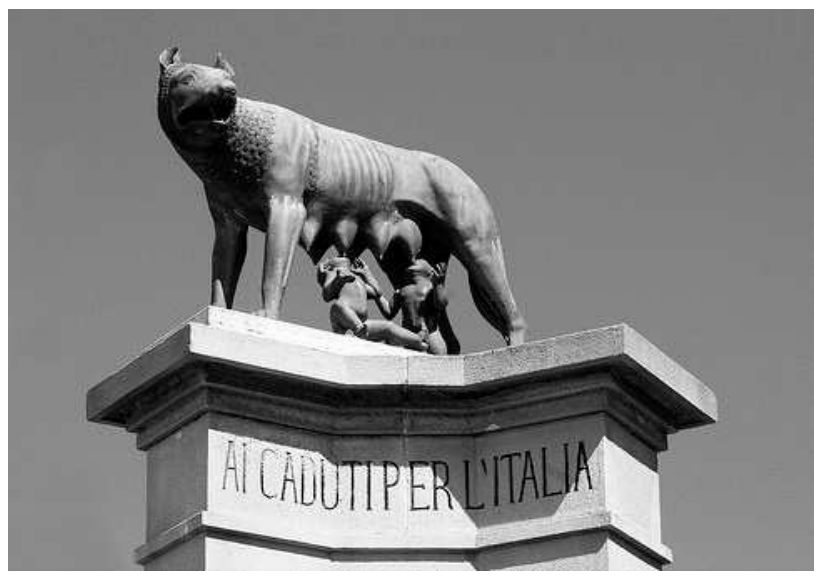

Fig. VII. Loba Capitolina en un monumento dedicado a los caídos por Italia, levantado bajo el gobierno de Mussolini en la ciudad de Roma.

Otros elementos míticos del pasado romano, con un sentido protector similar al de la Loba Capitolina, fueron recuperados durante la Antigüedad Tardía y mantuvieron vigente su significado hasta siglos después de la caída del Imperio Romano. Un caso clarísimo sería la iconografía de Cástor y Pólux; el culto de estas dos figuras de la mitología griega estaba presente en la ciudad de Roma desde mediados del siglo $\mathrm{V}$ a. C. cuando, según relata Dionisio de Halicarnaso en sus Antigüedades Romanas ${ }^{27}$, los Dióscuros se aparecieron en la batalla del Lago Regilo para liderar la caballería romana. El mito también los sitúa en el foro romano, y más concretamente en la fuente 
Yuturna, donde fueron a abrevar sus caballos. Por este motivo, el lugar de la fuente fue el emplazamiento de su primer templo titular.

Además los Dióscuros, en condición de gemelos, se asociaron a Rómulo y Remo, y como jinetes tuvieron una fuerte implicación militar que justificó su constante representación en numerosos reversos monetales ${ }^{28}$. Los Dióscuros servían para glorificar la imagen de Roma como potencia militar, $\mathrm{y}$ al igual que la figura de Rómulo, también fueron asimilados a la del propio emperador, fundamentalmente por su responsabilidad en el mando supremo del ejército y su papel como protector de la $U r b s^{29}$. No resulta casual que dos estatuas monumentales de los Dióscuros (Fig. VIII), probablemente de finales del siglo III, fueran elevadas en un lugar tan emblemático de Roma como el Capitolio ${ }^{30}$, tras el acondicionamiento urbanístico de la colina más importante de Roma, llevado a cabo por Michelangelo Buonarroti (14751564), que diseñó el pavimento, las escalinatas y los Palacios Capitolinos.

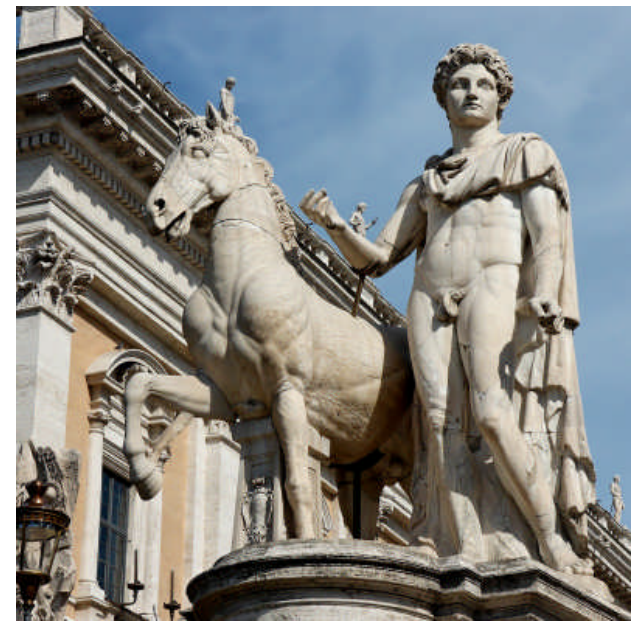

Fig. VIII. Escultura de Cástor, posiblemente de finales del siglo III. Acceso a la Piazza del Campidoglio. Roma.

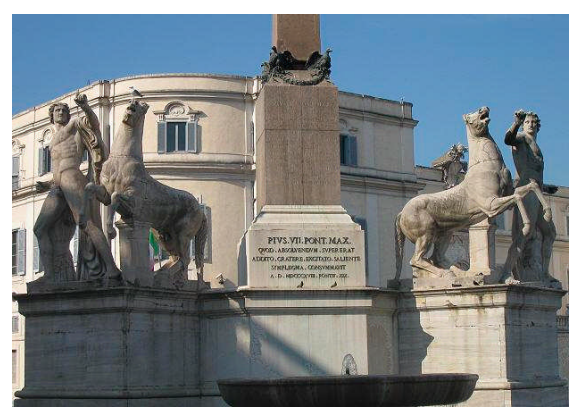

Fig. IX. Los Dióscuros flanqueando el obelisco de la Piazza del Quirinale. Posiblemente de la época de Caracalla. Aunque se desconoce su origen, es posible que procedan de las termas del citado emperador.

Lo mismo sucedió con otra pareja colosal de Dióscuros, de origen discutido, que fueron colocados a cada lado del obelisco que antaño ornó el Miliarium Aureum de Augusto, por parte de Domenico Fontana (1543-1607), sobre el monumento del Quirinal (Fig. IX), frente a la antigua residencia pontificia ${ }^{31}$. La imagen que la Roma del Renacimiento quería proyectar volvía a recurrir a elementos que, pese a su lejanía en el tiempo, aún mantenían vivo su significado. Los Dióscuros, como entidad dual pero indivisible, expresaban 
la idea de unidad deseada por el poder en la ciudad de Roma; un poder que, como hemos visto, se disputaban las dos entidades políticas que dominaban la ciudad: el poder eclesiástico desde el Quirinal, y el poder civil desde el Capitolio. Ambas instituciones quisieron tener cerca ese símbolo tan enraizado en la tradición clásica de la ciudad.

\section{CONCLUSIÓN}

Aunque en este artículo sólo se mencionan unos pocos elementos iconográficos que construyeron la imagen mítica de Roma, existen muchas otras representaciones que, de forma encubierta, y más allá de las evidencias visuales de Loba Capitolina, de Rómulo y Remo o los Dióscuros, sirvieron para expresar ideas relativas a la exaltación de las virtudes cívicas, la victoria, la seguridad o el poder. Una gran parte de ese corpus plagado de alegorías, emblemas y símbolos, que Europa ha empleado durante siglos, tiene su origen en Roma, es decir, en el Imperio y en su capital, convertida en el paradigma urbano más importante de nuestra cultura.

Una parte importante de la fascinación que aún genera en nosotros el mito de Roma procede de la herencia romántica de los artistas y eruditos que visitaron la ciudad en el siglo XIX, cuya atmósfera aún se respira en cada rincón de la ciudad. Roma, "ese vasto cementerio visitado por extranjeros", como afirmó Mariano Fortuny en una de sus cartas de 1858/185932, se ha conservado para nosotros en su dimensión más extraordinaria y, en cierto modo aún hoy, quienes nos dedicamos a su estudio, lo hacemos porque, más allá del conocimiento, sentimos cierto compromiso con la consumación de un mito.

\section{NOTAS}

* Becario de investigación FPI JCYL.

${ }^{1}$ VERnANT. J. P.: Mito y religión en la Grecia antigua. Ariel. Barcelona, 2001. P. 10.

${ }^{2}$ REYERO, C.: 'Palabras preliminares'. En REYERO, C. (Ed.): Roma y el ideal académico. La pintura en la Academia Española de Roma, 1873-1903. Real Academia de Bellas Artes de San Fernando. Madrid, 1992. P. 12.

${ }^{3}$ PASCHOUd, F.: Roma Aeterna. Études sur le patriotisme romain dans l'occident latin a l'époque des grandes invasions. Bibliotheca Helvetica Romana. Institut Suisse de Rome. Roma, 1967.

${ }^{4}$ RAND, E. K.: The Building of Eternal Rome. Harvard University Press. Cambridge, 1943. Pp. 3-35.

${ }^{5}$ PrATT, K. J.: 'Rome as Eternal'. The Journal of the History of Ideas, Vol. 26, No1. University of Pennsylvania Press. Filadelfia, 1965. P. 26.

${ }^{6}$ FAYER, C.: Il culto della Dea Roma. Origine e diffusione nell'Impero. Editrice Trimestre. Pescara, 1976. Pp. 107-110. 
${ }^{7}$ BEARE, R.: 'The meaning of the Oath by the safety of the Roman Emperor'. The American Journal of Philology, Vol. 99, Nº1. The John Hopkins University Press. Baltimore, 1978. Pp. 106-110.

${ }^{8}$ SALZMAN, M. R.: On Roman time. The codex-calendar of 354 and the rhythms of urban life in Late Antiquity. University of California Press. Berkeley, 1990. P. 153. Salus tuvo su propio templo en la colina del Quirinal, e incluso en época tardía fue incluida dentro del repertorio de leyendas monetales de Constantino y Magnencio como Salus Rei Publicae y Salus et Spes Rei Publicae.

${ }^{9}$ Charlesworth, M. P.: 'Pietas and Victoria. The Emperor and the Citizen'. The Journal of Roman Studies, Vol. 33, 1-2. Society for the promotion of Roman Studies. Londres, 1943. Pp. 1-10.

${ }^{10}$ Mcallen Green, W.: 'Notes on the Augustan deities'. The Classical Journal, Vol. 33, N². The Classical Association of the Middle West and South. Northfield, 1927. Pp. 86-93.

${ }^{11}$ Tito Livio: Ab Urbe Condita. Edición de A. FonTÁN. Consejo Superior de Investigaciones Científicas. Madrid, 1987. P. 9.

${ }^{12}$ Salzman, M. R.: On Roman time. P. 154. Los cultos de Rómulo/Quirino y Roma Aeterna fueron frecuentemente asociados al de Mars Invictus Pater.

${ }^{13}$ SCOTT, K.: 'The identification of Augustus with Romulus-Quirinus'. Transactions and Proceedings of the American Philological Association, Vol. 56. John Hopkins University Press. Baltimore, 1925. Pp. 82-105.

${ }^{14}$ SALZMAN, M. R.: On Roman time. P. 155. Este colegio sacerdotal pudo estar ligado en época tardía a los sacerdotes sacrae urbis, también identificados con el culto a Vesta.

${ }^{15}$ PRATT, K. J.: 'Rome as Eternal'. P. 27.

${ }^{16}$ Mommsen, T. y MeYer, P. M.: Codex Theodosianus. Weidmann. Zürich, 1971.

${ }^{17}$ JOHnSON, V. L.: 'Natalis Urbis and Principium Anni'. Transactions and Proceedings of the American Philological Association. Vol. 91. Baltimore, 1960. Pp. 109-120.

${ }^{18}$ SALZMAN, M. R.: On Roman time. P. 155. El Códice Teodosiano contiene numerosas informaciones acerca de las implicaciones políticas de muchas festividades recuperadas entre el siglo IV y el primer cuarto del siglo V en Roma. Para un estudio pormenorizado de la propaganda política contenida en este documento, CAÑIZAR PALACIO, J. L.: Propaganda y Codex Theodosianus. Dykinson. Madrid, 2005.

${ }^{19}$ SALZMan, M. R.: On Roman time. P. 184.

${ }^{20}$ FAYER, C.: Il culto della Dea Roma. Pp. 9-10.

${ }^{21}$ Ibid., Pp. 11-15.

${ }^{22}$ Magister, S. y SACCh, T.: Palazzo Primoli. Roma. Istituto Poligrafico e Zecca dello Stato. Roma 2005.

${ }^{23}$ Su cronología ha sido recientemente esclarecida tras la realización de unos análisis de composición del bronce, así como de un estudio definitivo sobre la técnica de fundición, por parte de los investigadores Anna Maria Carruba y Adriano la Regina. Los resultados del estudio han deparado fechas medievales (siglos XII-XIII), si bien no hay ninguna duda de que el primer modelo iconográfico fue etrusco. En cualquier caso, si la Loba de los Museos Capitolinos de Roma es una obra medieval, esto refuerza aún más la propuesta de este texto, ya que sería el mejor ejemplo de recuperación de un modelo iconográfico pagano con ob- 
jetivos claramente patrióticos en un contexto medieval. Sobre esta cuestión, PARISI PRESICCE, C.: La Lupa Capitolina. Catalogo della mostra. Electa. Milán, 2000.

${ }^{24}$ LÓPEZ SÁNCHEZ, F.: Victoria Augusti. La representación del poder del emperador en los reversos monetales romanos de bronce del siglo IV d. C. Institución 'Fernando el Católico'. Zaragoza, 2004. P. 50.

${ }^{25}$ Para una interpretación diferente, CRACCO RugGinI, L.: 'Il dittico di Rambona'. En AILLAGON, J. J. (Ed.): Roma e i Barbari. La nascita di un nuovo mondo. Skira. Milán, 2008. Pp. 568571.

${ }^{26}$ Sobre la recuperación de los valores 'imperiales’ bajo el gobierno de Mussolini, QUARTERMAINE, L.: 'Slouching towards Rome. Mussolini’s imperial vision'. En CORNELL, T. J. y LOMAS, K. (Ed.): Urban Society in Roman Italy. University College Press. Londres, 1995. Pp. 203-215.

${ }^{27}$ Dionisio de Halicarnaso: De Origine Urbis Romae.. Edición de J. H. Sautel. Les Belles Lettres. Paris, 1999.

${ }^{28}$ Los Dióscuros esconden una enorme variedad de lecturas simbólicas. Para Cumont, están relacionados con el mundo de ultratumba, pues participan alternativamente de la vida y la muerte, de la luz y la oscuridad, simbolizando dualidades cósmicas que constituyen un desafío al efecto destructor del tiempo. De esta forma, se explica su presencia en contextos funerarios, como relieves de sarcófagos, pero también en la moneda, puesto que la capacidad regeneradora que se les atribuye es también una característica del Estado Romano. CUMONT, F.: Recherches sur le symbolisme funeraire des Romains. Librairie Orientaliste Paul Geuthner. Paris, 1966. Pp. 67-94.

${ }^{29}$ SCOTT, K.: 'The Dioscuri and the Imperial Cult'. Classical Philology, Vol. 25, No4. The University of Chicago Press. Chicago, 1930. Pp. 379-380.

${ }^{30}$ PARISI PRESICCE, C.: 'I Dioscuri capitolini e l'iconografia dei gemelli divini in età romana'. En NisTA, L. (Ed.): Castores. L'immagine dei Dioscuri a Roma. De Luca Editore. Roma, 1994. Pp. 166-192.

${ }^{31}$ NISTA, L.: 'L'iconografia dei Dioscuri del Quirinale ed il restauro di Sisto V'. En NiSTA, L. (Ed.): Castores. L'immagine dei Dioscuri a Roma. De Luca Editore. Roma, 1994. Pp. 193-208.

${ }^{32}$ BONET-CORREA, A.: 'El viaje artístico en el siglo XIX'. En REYERO, C. (Ed.): Roma y el ideal académico. P. 34. 